\title{
Assessing the impact of using instant messaging in eLearning on the performance of teaching and learning in higher education
}

\author{
Aaron Bere \\ School of Information of Business IT and Logistics \\ RMIT University \\ Melbourne, Victoria, Australia \\ Email: aaron.bere@rmit.edu.au \\ Hepu Deng \\ School of Information of Business IT and Logistics \\ RMIT University \\ Melbourne, Victoria, Australia \\ Email: hepu.deng@rmit.edu.au \\ Richard Tay \\ School of Information of Business IT and Logistics \\ RMIT University \\ Melbourne, Victoria, Australia \\ Email: richard.tay@rmit.edu.au
}

\begin{abstract}
There are growing interests in improving teaching and learning performance through eLearning using specific emerging technologies in higher education. As a result, understanding the impact of using such technologies on the performance of teaching and learning is becoming important. This experimental study investigates the impact of eLearning using instant messaging on the performance of teaching and learning in higher education in developing countries. Pre-test and post-test surveys are used for collecting experimental data from participants to investigate the impact of using instant messaging on teaching and learning. Data analysis conducted quantitatively using SPSS reveals that eLearning using instant messaging improves teaching and learning. In particular, the use of instant messaging in eLearning is more effective than face-to-face teaching and learning with respect to the overall performance in the classroom. This leads to the conclusion that eLearning using instant messaging could transform teaching and learning in higher education in developing countries.
\end{abstract}

Keywords eLearning, instant messaging, performance in teaching and learning, student grades, interaction 


\section{Introduction}

Instant messaging is an emerging digital technology that offers real-time text and video transmission over the Internet. It is becoming increasingly popular with the rapid development of information and communication technologies (ICT), in particular the availability of smartphones (Bere and McKay, 2017). This is due to the benefits instant messaging offers to individual users including the ability to send text messages, audio, video chat, and group chat for free, the convenience and immediacy in communication regardless of time and geographical constraints unlike computer based communication services, and the capacity to provide an integrated platform for connecting various services such as electronic payments, online gaming, and social networking (Sun et al., 2017).

There is an increasing interest in the use of instant messaging in the development of effective electronic learning (eLearning) in higher education (Bere and Rambe, 2016; So, 2016; Murire and Cilliers, 2017). This is due to the high proliferation of instant messaging and the ability to support collaborative, ubiquitous, and personalised learning (Bere and Rambe, 2016). As a result, there are various projects that have been implemented on the adoption of instant messaging in higher education for improving teaching and learning (Bere and Rambe, 2016; So, 2016).

Much research has been done that shows the potential benefits for adopting eLearning using instant messaging in higher education (Bere and Rambe, 2016; So, 2016). There is, however, lack of studies that focus on investigating the impact of using instant messaging on teaching and learning performance (Bere and McKay, 2017), especially in developing countries in which eLearning resources are limited (Rambe and Bere, 2013). There are mixed findings with respect to the effectiveness of eLearning using instant messaging in the literature. Some studies, for instance, argue that the use of eLearning using instant messaging has positive effects on teaching and learning in higher education (Bere and Rambe, 2016; So, 2016). Some other studies report various drawbacks of using instant messaging in eLearning including the negative impact on writing because students tend to overlook an appropriate use of vowels and punctuation, prone to high levels of distraction while learning, and lack of organisation of the discussions held over these applications (Fewkes and McCabe, 2012; Wang, Woo and Quek, 2012). This shows that there is a need for better understanding the impact of using instant messaging on the performance of teaching and learning in higher education.

The aim of the study is to investigate the impact of eLearning using instant messaging on the performance of teaching and learning in higher education in developing countries. The study follows a pre-test and post-test control group experimental design in order to achieve the purpose of the study. Pre-tests and post-test surveys are used for collecting data from undergraduate students in South Africa. The collected data are analysed using SPSS. The results show that eLearning using instant messaging improves teaching and learning. Furthermore, the use of instant messaging in eLearning is more effective than face-to-face teaching and learning with respect to the overall performance in the classroom. This study contributes to the ongoing debate on how to improve teaching and learning using emerging technologies. The findings of this study can lead to better adoption of eLearning using instant messaging in higher education.

In what follows, the second section provides a review of the related literature about the use of instant messaging in eLearning. The third section addresses the research question and the development of hypotheses in the study. The fourth section presents the methodology used in this study. The fifth section provides a quantitative data analysis using SPSS. This is followed by the research findings and discussion. Finally, the conclusion of the study is provided.

\section{Literature Review}

eLearning can be approached from different viewpoints including the educational paradigm and the delivery orientation (Lee, Yoon and Lee, 2009; Sek et al., 2016). Educational philosophers view eLearning as a self-regulated knowledge acquisition practice achieved through various learning processes including interactions using digital technologies (Lee, Yoon and Lee, 2009; Sek et al., 2015). Delivery-oriented research treats eLearning as the delivery of teaching and learning material in various formats including documents, texts, audios, and videos through ICT (Lee, Yoon and Lee, 2009). In this study, eLearning is referred to as a teaching and learning approach that focuses on the needs and abilities of students through adopting digital technologies to provide students with electronic content asynchronously or synchronously in a blended setting at anytime and anywhere (Bere and Rambe, 2016).

The popularity of instant messaging in eLearning provokes the need to develop new modes of eLearning systems in higher education (So, 2016). This is because instant messaging offers numerous 
benefits to teaching and learning including the ability to facilitate the flow of information and the sharing of information among students and teachers, the capacity to provide anywhere and anytime learning through using smartphones, the capability of combining audio, text, and video communications in a user-friendly multi-modal platform that allows students to interact through message exchanges at no cost or minimal cost. In particular, students can easily record an audio, take a photo, and record a video, attach these files and send them easily to other students as learning materials (Rambe and Bere, 2013; Sun et al., 2018). This leads to an increased acceptance of instant messaging in eLearning for teaching and learning in higher education.

Robinson et al. (2015) conduct a study in the United Kingdom about the potential of using instant messaging in promoting teaching and learning in higher education. The study reveals that instant messaging facilitates the development of a social presence among students in teaching and learning in higher education. Such a social presence creates an immediate connection between students, therefore leading to the improvement of teaching and learning. In particular, this study recognises various affordances of instant messaging in teaching and learning including the promptness of the immediate arrival of new messages, the easiness of uploading and downloading text, audio, and video massages, the availability of user-friendly interfaces for collaborative learning, the ability to arrange messages in a chronological order to facilitate the finding of the original thread, and the capacity to form groups without the intervention of the third party. The study, however, does not directly investigate the impact of instant messaging on the performance of teaching and learning in higher education.

So (2016) investigates the effectiveness of eLearning using instant messaging in higher education at Hong Kong. The study utilises a mixed-methods approach including experimental and control groups, and surveys. It reveals that instant messaging improves the performance of teaching and learning. The study further shows that there is an increasing acceptance of instant messaging in eLearning as a teaching and learning tool in higher education at Hong Kong. Such a study is useful for better understanding the impact of using instant messaging in eLearning on the performance of teaching and learning in higher education. The study, however, is conducted in the context of developed countries in which the overall environment for the use of instant messaging is very much different from the context of developing countries.

Awada (2016) explores the effectiveness of eLearning using instant messaging on the performance of teaching and learning in developing countries with respect to the proficiency of critique writing in higher education. The study follows a pre-test and post-test control group experimental design. It reveals that instant messaging is more effective in enhancing the critique writing proficiency of the participants through increasing the motivation of students for learning. Overall this study provides better understanding of the impact of using instant messaging in eLearning on the performance of teaching and learning. It is, however, limited in the generalisability of the research findings due to the focus of the study only in teaching and learning of the English language in higher education.

In South Africa, Rambe and Bere (2013) investigates the effectiveness of eLearning using instant messaging in higher education with the adoption of a qualitative approach. Such a study is conducted within the framework for the rational analysis of mobile education (Koole, 2009). It reveals that the use of instant messaging in eLearning improves teaching and learning in various ways including intensified students' academic participation, developed learning communities for knowledge creation, and increased knowledge sharing capabilities. This leads to improved user perceptions that influence the intention of students to adopt eLearning using instant messaging in higher education.

Rambe and Bere (2013) explore the challenges of eLearning using instant messaging in higher education for improving teaching and learning. This leads to the identification of specific challenges to the effective use of instant messaging including the presence of slow download of large audio and video files, the struggle of students in expressing themselves in English, the existence of student fears of increased workloads through responding to peers' queries, the need for giving critiques based on indepth understanding, the pressure of collaborative engagements, and the disturbance of instant messaging notifications. This study is valuable for better understanding the use of instant messaging in eLearning. This is because the identifications of the challenges can help eLearning practitioners develop more effective strategies and policies for improving the use of instant messaging in eLearning.

Murire and Cilliers (2017) conduct a study in South Africa to investigate the critical factors that influence the adoption of eLearning using instant messaging in higher education following the unified theory of acceptance and use of technology (Venkatesh et al., 2003). The study argues that the adoption of eLearning using instant messaging could improve teaching and learning through improved communication between students and lecturers. This leads to the identification of various critical factors for the adoption of eLearning using instant messaging including performance expectancy, 
social influence, effort expectancy and behavioural intention. This study is useful in better understanding the critical factors for the adoption of instant messaging in eLearning for improving teaching and learning. There is, however, lack of empirical studies on the impact of using instant messaging in eLearning on teaching and learning performance in higher education with the use of quantitative approaches.

The studies above examine the impact of using instant messaging on the performance of teaching and learning in higher education. These studies show that performance in teaching and learning is measured in various ways including social presence, student grades, student perceptions, and learning activities such interactions. The literature review shows that the performance in teaching and learning influence adoption of eLearning in higher education. However, there is little research in the investigation of performance in teaching and learning in developing countries mainly using student grades.

\section{Research questions and hypotheses development}

This study aims to investigate the impact of eLearning using instant messaging on the performance of teaching and learning in higher education in developing countries. To adequately achieve this objective, the main research question for the study is formulated as follows: How effective is the use of instant messaging in eLearning for improving teaching and learning in higher education in developing countries?

To successfully address this research question, two hypotheses have been developed with respect to the relationship between the use of instant messaging and the performance of teaching and learning in higher education in developing countries. Such hypotheses are to be tested through the use of the control group in order to adequately assess the impact of using instant messaging in eLearning on the performance of teaching and learning in higher education.

The performance of teaching and learning in eLearning can be measured from different perspectives including social presence, levels of interaction, student satisfaction, and student grades (Rambe and Bere, 2013; Robinson et al., 2015; So, 2016). Social presence is used to measure the performance of teaching and learning as the degree at which a communication medium mimics the characteristics of face-to-face interaction (Park, Cho and Lee, 2014). Use interaction is adopted to measure the performance of teaching and learning in which interaction is defined as a two-way communication between individuals, either on an individual or group basis during teaching and learning (Jesus and Moreira, 2009). User satisfaction is used to measure the performance of teaching and learning as the degree of student's opinion about the potential of eLearning to improve teaching and learning (Vasileva-Stojanovska et al., 2015). Student grades are a standardised measurement of varying levels of achievements in a course based on an individual's scores (Warne et al., 2014). They are commonly used in measuring the performance of teaching and learning, in particular in developing countries like South Africa.

There is a common recognition that the performance of teaching and learning is positively associated with the adoption of eLearning in higher education. Rudman (2017) conduct a study in South Africa to examine the effect of eLearning on the performance of teaching and learning. The study measures performance using student grades. A quasi-experimental design with a pre-test-intervention-post-test repeated measure timeline method is adopted. The findings reveal that eLearning has positive effects on the performance of teaching and learning. Bere and McKay (2017) conduct a study in South Africa to assess the impact of specific eLearning technologies on the performance of teaching and learning. The study measures performance using student grades. A quasi-experimental design consisting of eLearning using LMS versus eLearning using instant messaging were conducted. Data was collected using pre-test and post-test surveys. The findings show that although both eLearning interventions improve performance of teaching and learning, eLearning using LMS is more effective. Due to the social presence, interaction capabilities and students' satisfaction of eLearning using instant messaging, individuals who utilise these digital technologies should obtain higher grades. Based on this background the following hypothesis is developed.

H1. eLearning using instant messaging positively influence teaching and learning performance.

Traditional face-to-face teaching approaches are the most commonly used instructional method predominantly in developing countries (Bere and McKay, 2017). Techniques such as small group work contribute to the popularity of traditional face-to-face teaching. This is due to numerous benefits including capacity to empower students on how to interact, provision of opportunities to develop 
productive dispositions and intellectual autonomy, and ability to facilitate interpersonal skills development and appreciation for engaging in democratic processes (Jansen, 2012). Contrarily, traditional face-to-face has numerous challenges including restrictions to learning constrained by space and time, students' attention diminishes quickly during lectures, costly, and use of large amounts of paper which has implications on the environment (Bere and McKay, 2017). As a result of these challenges eLearning is replacing traditional teaching methods in higher education. This is due to the promises eLearning offers including ability to support anywhere and anytime learning, provision of authentic collaborative learning facilitated by effective social presence, quick provision of feedback, cost effective, and environment friendly (So, 2016; Sun et al., 2018). This leads to the development of understandings that eLearning is an effective alternative to traditional face-to-face teaching and learning. Based on this background the following hypothesis is developed.

H2. eLearning using instant messaging has better teaching and learning performance than face-toface teaching and learning.

\section{Research Design and Methodology}

This paper aims to investigate the impact of eLearning using instant messaging on the performance of teaching and learning in higher education in developing countries. Two research hypotheses have been developed as above. To effectively test the hypothesis, linear regression and ANOVA tests are conducted on the data collected through the use of control groups in a higher education institution in South Africa.

To adequately answer the research question, a pre-test and post-test control group experimental design is adopted in the study. The study follows several specific steps including face-to-face lecture, pre-test and post-test control experiments in a form of eLearning tutorials versus traditional face-toface based group tutorials. These steps are elaborated on Figure 1.

All participants at each research site were requested to gather in a single lecture theatre in which they received a normal lecture on SQL development within a database management course. The lecture was offered by one of the research investigators. The lecture took 45 minutes.

Pre-Test: During the same week participants received a face-to-face lecture, a paper-based pre-test was administered to all participants in a lecture theatre. This instrument was developed to establish prior domain knowledge.

\section{$\downarrow$}

On the following week, two parallel tutorials were organised including the experimental and control groups. Participants were randomly placed in the treatment groups. The tutorials covered previous week's class.

Experimental group ( 51 participants)

Participants are placed in WhatsApp small groups of up to 10 including students and facilitator. The facilitator initiates the academic interaction by posting questions to the WhatsApp instant messaging cyber group. Each participant has the opportunity to contribute. Students are allowed to post questions too and provide feedback to their peers as well as academically supporting their group members. Interactions took place in various forms including text, audio, images, and video.

The facilitator actively participates in the tutorial for 45 minutes per day. Students are encouraged to extend the peer-interaction outside learning hours. Students were advised to take note of problems they could not solve and seek clarification from the facilitator in the next tutorial.

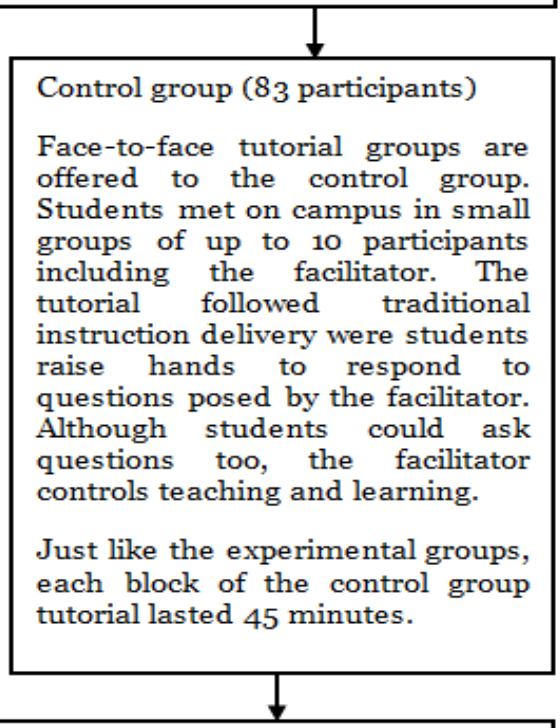

Post-Test: After five sessions of tutorials in week two, the post-test was administered to all participants who completed the experiment to measure students' knowledge after the experiment. 
Figure 1: Research steps

The data collection survey instruments for the study consist of pre-test and post-test. These instruments are developed based on Gagné (1985) learned capabilities including intellectual skills, cognitive strategy, and verbal information. In order to develop valid and reliable instruments, an instructional matrix developed by Gagné (1985) is engaged. The instructional matrix is directly used to guide the development of a pre-test which tests nine learning domains associated with the acquisition of database SQL query concepts. The database SQL query learning domains are listed vertically on the left-hand side of the instructional matrix (the y-axis), while the five instructional objectives are listed horizontally (the $\mathrm{x}$-axis) from band-A to band-E. The level of instructional objectives complexity increased from band-A to band-E. The nine listed learning domains include database terms, database operations, database types, components of SELECT clause, FROM clause, conditional filtering, logic operations, aggregate functions, and developing queries.

Pre-Test: This instrument establishes prior domain knowledge, hence a paper based pre-test is completed based on participants' knowledge gained during their normal lectures. This implies that, a pre-test is conducted before accessing treatments. To avoid pressure and stress, the pre-test items are ordered from easiest to the most difficult.

The pre-test instrument consists of 38 test-items. It has 18 dichotomous and 20 partial credit testitems. Dichotomous refers to a scoring technique that utilises either a 'o' or ' 1 '. A test-item is scored 'o' if the answer is either incorrect or blank (left unanswered), while a score of ' 1 ' is allocated when a correct answer has been given. Therefore, the dichotomous scoring system is applied for test-items that require clear and easy understanding questions. Partial credit scoring technique is used for complex questions that required an ordered sequence of steps to be followed to get to a solution and could not be answered by a distinct response. These item-tests cannot be scored by assigning either a 'o' or ' 1 ' because partially correct responses can be obtained.

Post-Test: Just like the pre-test, the post-test instrument consists of 38 test-items. It has 18 dichotomous and 20 partial credit test-item sores. The post-test instrument is developed based on the instruction matrix principles too. This instrument is designed in such a way that its content is closely related to that of a pre-test. The test-items in the post-test are randomly ordered and the wording for the two instruments is not identical. The rationale behind such differences is to reduce memory effects on post-tests. The researcher carefully rephrased post-test test-items keeping in mind that they should measure the same learning content with the pre-test test-items.

Content validity is established on both survey data collection instruments prior to the experiments. The process involve 16 database experts including 4 database developers, 4 business intelligence specialist, 4 university lecturers in South Africa, and 4 database administrators. These experts are contacted by e-mail and requested to participate in the instrument testing process. Fourteen participants agreed to take part in the study but ten provided content validity feedback of the instruments. Seven questions were amended including two dichotomous and five partial credit testitems in order to improve their readability, clarity and comprehensiveness (Bolarinwa, 2015).

To ensure reliability of the instruments, a pilot study was conducted using 28 undergraduate students enrolled for database management courses at one of the research sites. Students who participated in the pilot study were not considered in the main experiment. The purpose of this instrument testing process is to calibrate and validate the reliability of the research procedure, using the QUEST Interactive Test Analysis System (Adams \& Khoo, 1996). The pilot study pre-test item-fit map presented on figure 2 shows that test-items 9 and 33 over-fits the Rasch model. such test-items should be eliminated (Adams and Khoo, 1996). Further test were conducted to ascertain their invalidity.

The test-items discrimination was observed. Wu and Adams (2007) recommend a test-item discrimination should be at least 0.2. Test-items 9 and 33 obtained a discrimination value of 0.66 each. Therefore, the test-items are discriminating well between "able" and "not able" participants. In relation to this pilot study, the test-items 9 and 33 provide very high discrimination effect on the measurement of database knowledge acquisition when it is correlated with the overall score of the test. A conclusion is made that Test-items 9 and 33 are important abilities which should be tested novice database SQL developers, hence such test-items should not be deleted from the instrument. Therefore, a decision was made not to remove them. 


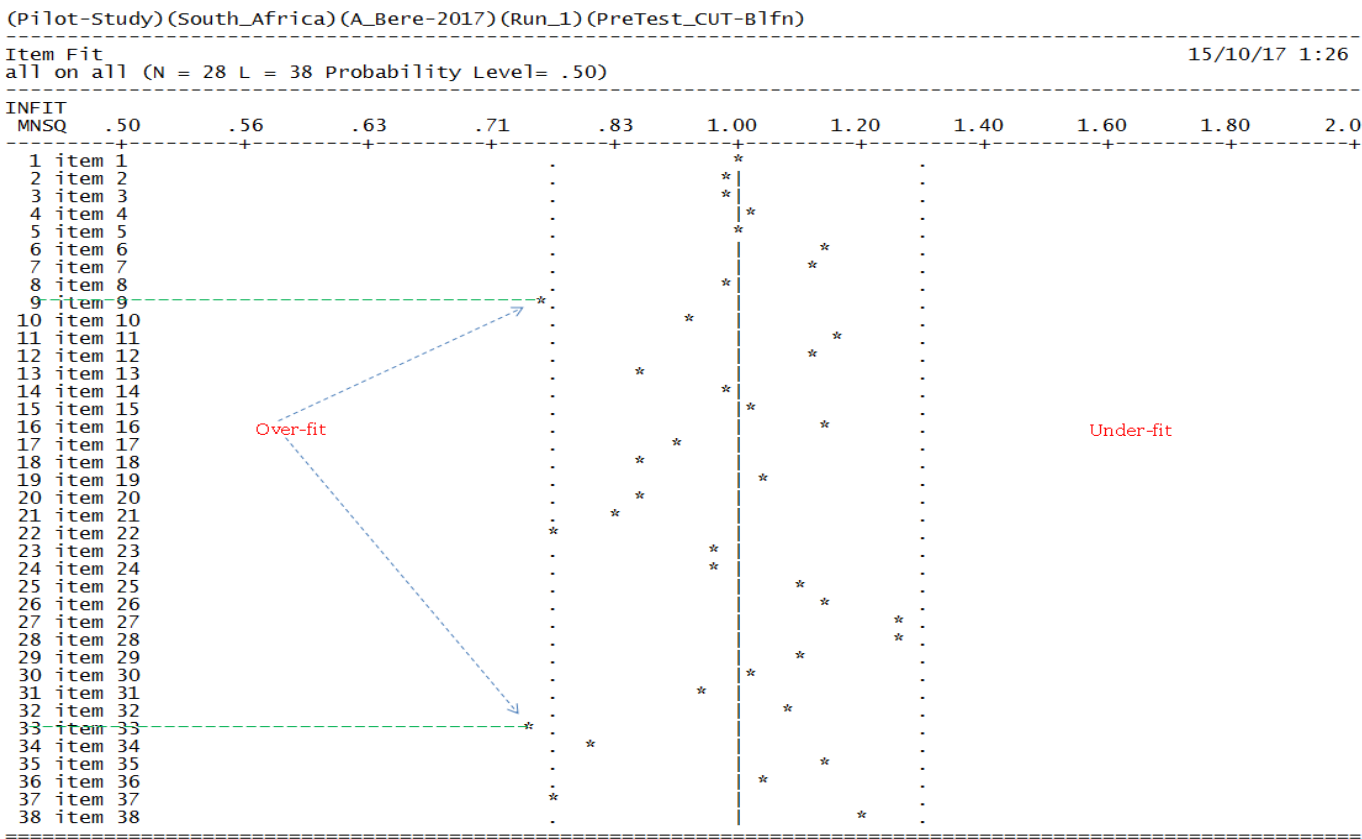

Figure 2: pilot study pre-test item-fit

Although test-item 9 and 33 of the pilot study pre-test did not fit the Rasch model, the instrument displays sufficient internal consistency. According to Wu and Adams (2007) the recommended internal consistency should be at least 0.70 . The pre-test's internal consistency is 0.82 which surpasses the recommended threshold. Such results show that the survey instrument is reliable.

The paper-based survey was conducted at two South African universities of Technology between March 2017 and May 2017. The target population from both universities is undergraduate IT enrolled in database management introductory course. A total of 141 questionnaires were distributed. Seven were discarded due to missing responses. Females are the majority consisting of $59 \%$ of the participants' population (134 participants).

Participants' ages are categorised in four groups. The 22-25 years age group is the most popular with 88 participants while the 30 years and above category is the least popular with 10 participants. The 1821 years and 16-29 years' participants are 22 and 14 respectively.

\section{Data Analysis}

The study experiment consists of control group $\mathrm{N}=83$ and experiment group $\mathrm{N}=51$ participants. To minimise bias, participants are randomly selected into the study groups. Control group involves small group face-to-face interactions. Control group mean and standard deviation are 10.20 and 6.758 respectively while experiment group obtains higher values of mean $=18.65$ and standard deviation $=$ 8.079. A higher mean suggests that experiment group performed better than control group. A higher standard deviation shows that experiment group data is largely dispersed compared to control group data. Table 1 below presents the mean and standard deviations of the study.

\begin{tabular}{llll}
\hline Treatment & $\mathbf{N}$ & Mean & Std. Deviation \\
\hline Control group & 83 & 10.20 & 6.758 \\
Instant messaging & 51 & 18.65 & 8.079 \\
Total & 134 & 13.42 & 8.344 \\
\hline
\end{tabular}

Table 1. Mean and standard deviation

A linear regression was conducted to depict the teaching and learning performance impacts of the eLearning initiative using instant messaging. Experimental group results $(b=8.44$, s.e $=1.30, p<.00)$ shows that eLearning using instant messaging predict better performance in teaching and learning. Correspondingly, the control group results $(\mathrm{b}=10.21$, s.e $=.80, \mathrm{p}<.00)$ reveals that traditional teaching methods predict better performance in teaching and learning. eLearning using instant 
messaging account for $24.3 \%$ of the performance in teaching and learning $\left(\mathrm{R}^{2}=.243\right)$ which shows that the model relatively fits the data. Table 2 below presents results of the study linear regression.

\begin{tabular}{lccccc}
\hline & \multicolumn{5}{c}{ Step 1 } \\
\cline { 2 - 6 } Variables & $\mathrm{b}$ & s.e & $\beta$ & $\mathrm{p}$ & $\mathrm{t}$ \\
\hline Constant (control group) & 10.21 & .80 & & .00 & 12.76 \\
Instant messaging & 8.44 & 1.30 & .49 & .00 & 6.51 \\
$\mathrm{R}^{2}$ & $24.3^{* * * *}$ & & & & \\
$\Delta \mathrm{R}^{2}$ & $24.3^{* * *}$ & & & & \\
\hline
\end{tabular}

Table 2. Linear regression results

The second hypothesis postulates that eLearning using instant messaging has better teaching and learning performance than face-to-face teaching and learning. ANOVA was employed to examine this hypothesis. The ANOVA results show hypothesis 2 of this study is significant $(\mathrm{F}=42.400, \mathrm{p}<.000)$. This finding means that eLearning using instant messaging is more effective that traditional teaching and learning methods. Table 3 presents ANOVA test results of the study.

\begin{tabular}{cccccc}
\hline Model & Sum of Squares & df & Mean Square & F & Sig. \\
\hline Regression & 2251.432 & 1 & 2251.432 & 42.400 & $.000 b$ \\
Residual & 7009.165 & 132 & 53.100 & & \\
Total & 9260.597 & 133 & & & \\
\hline
\end{tabular}

Table 3. ANOVA test results

\section{Discussion}

This section presents a summary of the main findings of this study. These findings are organised with respect to the two hypotheses developed above. The first hypothesis postulates that eLearning using instant messaging positively influences teaching and learning performance. As indicated on Table 2, this is supported which suggests that eLearning using instant messaging can positively influences the teaching and learning performance. This finding is consistent with that of So (2016) who reveals that instant messaging mediated eLearning systems could improve students' performance. Such improvement in teaching and learning could be caused by sharing knowledge and learning resources outside school hours (So, 2016). This shows the significance of various instant messaging characteristics including ability to form of cohorts for teaching and learning, interaction at no cost, and ubiquitous learning (Rambe and Bere, 2013).

The second hypothesis assumes that eLearning using instant messaging has better teaching and learning performance than traditional teaching and learning methods. The findings of the study reveal that this hypothesis is significant $(\mathrm{F}=42.400, \mathrm{p}<.000)$. This finding is consistent with the research in eLearning using instant messaging (Rambe and Bere, 2013; Robinson et al., 2015; So, 2016). Robinson et al. (2015), for example, reveal that various instant messaging technology characteristics influence better performance in teaching and learning than other instructional methods. These characteristics include the promptness of the immediate arrival of new messages, the easiness of uploading and downloading different formats of massages, the availability of user-friendly interfaces, the ability to arrange messages in a chronological order to facilitate the finding of the original thread, and the capacity to form groups without the intervention of the third party. Furthermore, the capacity of instant messaging to support teaching and learning anywhere and anytime makes it better than traditional face-to-face instructional methods (Rambe and Bere, 2013). This suggests the importance of the technology affordances of instant messaging on improving the performance of teaching and learning.

The findings of this study corroborates Rambe and Bere (2013)'s views that eLearning using instant messaging offer more effective collaborative learning settings resulting in better teaching and learning performance impacts. Rambe and Bere (2013) encourage South African higher education educators and students to adopt instant messaging for supporting teaching and learning activities.

The contributions of this study are twofold. Firstly, the study provides a better understanding of the performance of teaching and learning using instant messaging. Secondly, this study provides insights that eLearning using instant messaging is more effective than traditional face-to-face teaching and learning methods with respect to performance in teaching and learning. The research findings in this 
study have practical implications for higher educational institutions particularly in developing countries in their decision to transform teaching and learning through better adoption of eLearning.

\section{Conclusion}

The study examines the effectiveness of eLearning using instant messaging in higher education. Findings reveal that both face-to-face and eLearning using instant messaging enhance teaching and learning. The study shows that eLearning using instant messaging is more effective than face-to-face teaching and learning.

The major limitation of the study is that the sample is selected from a single department of two universities in South Africa. To generalise the findings, the sample should be extended. Future study can be conducted to investigate the factors causing performance in teaching and learning using instant messaging.

\section{References}

Adams, R. and Khoo, S. 1996. Quest Version 2.1: The Interactive Test Analysis System. Camberwell, Victoria, Australia: ACER press

Awada, G. 2016. Effect of WhatsApp on critique writing proficiency and perceptions toward learning. Cogent Education (3:1) pp 1-25.

Bere, A. and McKay, E. 2017. Investigating the impact of ICT tutorial strategies to promote improved Database knowledge acquisition, The 28th Australasian Conference on Information Systems, Hobart, Australia: University of Tasmania.

Bere, A. and Rambe, P. 2016. An empirical analysis of the determinants of mobile instant messaging appropriation in university learning. Journal of Computing in Higher Education (28:2) pp 172198.

Bolarinwa, O. A. 2015. Principles and methods of validity and reliability testing of questionnaires used in social and health science researches. Nigerian Postgraduate Medical Journal ( 22:4) pp 195-201.

Fewkes, A. M. and McCabe, M. 2012. Facebook: Learning tool or distraction? Journal of Digital Learning in Teacher Education (28:3) pp92-98.

Gagné, R. 1985. The Conditions of Learning and Theory of Instruction. New York, NY: Holt, Rinehart and Winston.

Jansen, A. 2012. Developing Productive Dispositions during Small-Group Work in Two Sixth-Grade Mathematics Classrooms: Teachers' Facilitation Efforts and Students' Self-reported Benefits. Middle Grades Research Journal (7:1) pp 37-56.

Jesus, R. A. F. and Moreira, F. J. L. (2009) E-Learning and Solidarity: The Power of Forums, Handbook of Research on Social Dimensions of Semantic Technologies and Web Services: IGI Global:448-467.

Koole, M. L. 2009. A model for framing mobile learning. Mobile learning: Transforming the delivery of education and training (1:2) pp 25-47.

Lee, B.-C., Yoon, J.-O. and Lee, I. 2009. Learners' acceptance of e-learning in South Korea: Theories and results. Computers \& Education (53:4) pp 1320-1329.

Murire, O. T. and Cilliers, L. 2017. Social media adoption among lecturers at a traditional university in Eastern Cape Province of South Africa. South African Journal of Information Management (19:1) pp 1-6.

Park, S., Cho, K. and Lee, B. G. 2014. What makes smartphone users satisfied with the mobile instant messenger?: Social presence, flow, and self-disclosure. International Journal of Multimedia and Ubiquitous Engineering (9:11) pp 315-324.

Rambe, P. and Bere, A. 2013. Using mobile instant messaging to leverage learner participation and transform pedagogy at a South African University of Technology. British Journal of Educational Technology (44:4) pp 544-561. 
Robinson, L., Behi, O., Corcoran, A., Cowley, V., Cullinane, J., Martin, I. and Tomkinson, D. 2015. Evaluation of Whatsapp for promoting social presence in a first year undergraduate radiography problem-based learning group. Journal of Medical Imaging and Radiation Sciences (46:3) pp 280-286.

Rudman, E. M. P. 2017. Biomechanics for first year occupational therapy students: enriching learning using an E-learning resource. South African Journal of Occupational Therapy (47:1) pp 36-40.

Sek, Y. W., Deng, H., McKay, E. and Qian, M. 2016. Exploring the impact of learning styles on the acceptance of open learner models in collaborative learning. International Journal of Systems and Service-Oriented Engineering (IJSSOE) (6:3) pp1-15.

Sek, Y. W., Deng, H., McKay, E. and Xu, W. Investigating the determinants of information sharing intentions of learners in collaborative learning. International Conference on Web-Based Learning: Springer, 87-97.

So, S. 2016. Mobile instant messaging support for teaching and learning in higher education. The Internet and Higher Education (31:2016) pp 32-42.

Sun, Y., Liu, D., Chen, S., Wu, X., Shen, X.-L. and Zhang, X. 2017. Understanding users' switching behavior of mobile instant messaging applications: An empirical study from the perspective of push-pull-mooring framework. Computers in Human Behavior (75:2017) pp 727-738.

Sun, Z., Lin, C. H., Wu, M., Zhou, J. and Luo, L. 2018. A tale of two communication tools: Discussion forum and mobile instant messaging apps in collaborative learning. British Journal of Educational Technology (49:2) pp 248-261.

Vasileva-Stojanovska, T., Malinovski, T., Vasileva, M., Jovevski, D. and Trajkovik, V. 2015. Impact of satisfaction, personality and learning style on educational outcomes in a blended learning environment. Learning and Individual Differences (38:2015) pp 127-135.

Venkatesh, V., Morris, M. G., Davis, G. B. and Davis, F. D. 2003. User acceptance of information technology: Toward a unified view. MIS quarterly (27:3) pp 425-478.

Wang, Q., Woo, H. L. and Quek, C. L. 2012. Exploring the affordances of Facebook for teaching and learning. International Review of Contemporary Learning Research (1:1) pp 23-31.

Warne, R. T., Nagaishi, C., Slade, M. K., Hermesmeyer, P. and Peck, E. K. 2014. Comparing weighted and unweighted grade point averages in predicting college success of diverse and low-income college students. NASSP Bulletin (98:4) pp 261-279.

Wu, M. and Adams, R. 2007. Applying the Rasch model to psycho-social measurement: A practical approach. Educational Measurement Solutions Melbourne.

Copyright: (C) 2018 authors. This is an open-access article distributed under the terms of the Creative Commons Attribution-NonCommercial 3.0 Australia License, which permits non-commercial use, distribution, and reproduction in any medium, provided the original author and ACIS are credited. 